\title{
相馬ジュラ紀層群産の鳥の巣二枚貝化石群について
}

\author{
田村实* \\ (1958 年 12 月 10 日受理)
}

\section{On the Torinosu Pelecypod-fauna in the Jurassic Group of Soma in Fukushima Prefecture}

Minoru Tamura

\section{(Abstract)}

This paper outlines the general aspect of the Upper Jurassic pelecypod-fauna in the Soma district, Fukushima Prefecture, the salient features of which are summarized as follows:

1. The Nakanosawa and Koyamada formations comprise four fossil zones (6-8th zones) and two fossil zones $(9,10$ th zones) respectively. These zones are shallow water sediments including sandy, calcareous and shaly facies (Fig. 1), each of which bears characteristic fossils.

2. The fauna consists of 22 families, 38 genera and 61 species (Table $1 \& 2$ ). Its chief components are the Pectinidae, Pteriidae, Astartidae and Trigoniidae. Inoceramus and Aucella typical of the shaly facies, ex. the Spiti shale, are absent in the fauna. As shown in Table 3, nine species are known from the Upper Jurassic of Himalaya, Ethyopia and Europe. Whether the fauna belongs to the Himalayan or Ethyopian faunal province is a matter of dicussion because the Eligmus-Gryphaea fauna typical of the Tethyan province is absent in this fauna, because the Trigonians are different between this and the Tethyan fauna and because endemic elements like Somapecten, Neoburmesia, Somapteria and Nipponitrigonia are contained in the fauna. On the other hand, the Mindoro and Borneo islands yield some fossils, very similar to the Soma ones. They are mostly Trigonians. In future these faunas may reveal their relation with the Soma fauna. Certain features of this fauna suggest its independence from the Tethyan faunas. It may constitute a faunal province together with those of Borneo and Mindoro Islands.

3. The fauna is quite different from the Upper Jurassic ones of the Upper Kuzuryu and the southern Kitakami region, if some Trigonians are overlooked.

4. The fauna is classified with reference to their habits and shown in Table 4.

\section{1 まえがきと層序の大要}

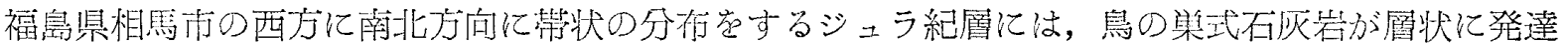
するので古来存名である。との区域の地窂は正谷清（1950）の研究によつてその概要が明らかにされ

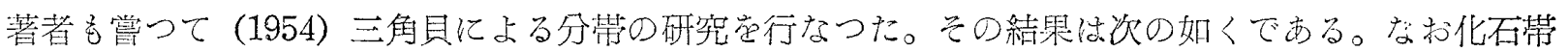

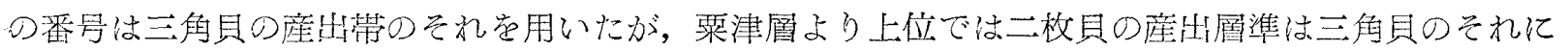
一致する。

* 熊本大学教育学部

地貨学雑誌 第 65 巻 第 764 号 1959 年 5 月 


\begin{tabular}{|c|c|c|c|c|c|c|c|c|}
\hline 小 & 山田 & 㬝 & \multirow{2}{*}{ 整 } & & \multirow{2}{*}{ 合 } & 頁 & 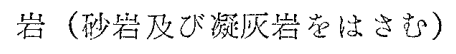 & 9-10 化石斾 \\
\hline 富 & 沢 & 層 & & & & 砂 & 岩（頁岩足はさむ） & \\
\hline ศ & の 沢 & 層 & IE. & & 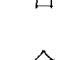 & 砂 & 岩（下部）及び石死䇹（上部） & 5 -8 化石带 \\
\hline 杤 & 泾 & 㬝 & & & $\sqrt{2}$ & 砂 & 岩（頁斯営はさむ） & \\
\hline 須 & 啙 & 㬝 & & & & 砂 & 岩（賈䇹をはさむ） & 3,4 化不棎 \\
\hline 獎 & 㴖 & 層 & & & & 頁 & 岩（砂宕聕はさむ） & 1,2 化盾滞 \\
\hline 羽 & 山 & 䍛 & & & 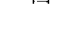 & & 頁岩 & \\
\hline
\end{tabular}

相馬ジュラ紀層の地質時代てついては，清水三郎（1930）小林貞一（1935）によつて論ぜられ，正

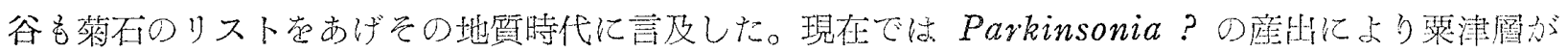

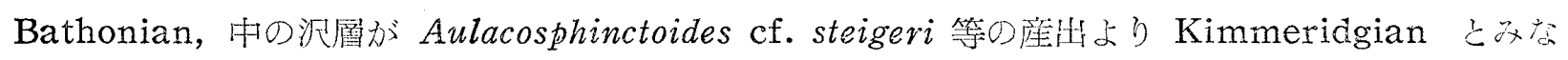
されている。また小山田層は正谷により Tithonian と考光られている。てれらの封代党確定するに

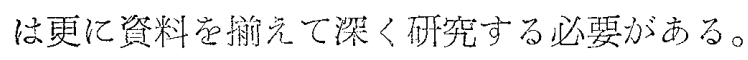

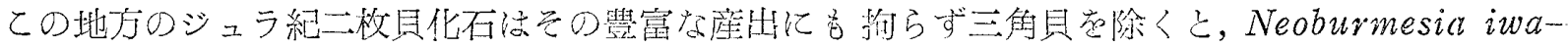
kiensis Y $\mathrm{ABE}$ and SAto(1942) L Somapecten kamimanensis KIMURA, Aequipecten ogawensis

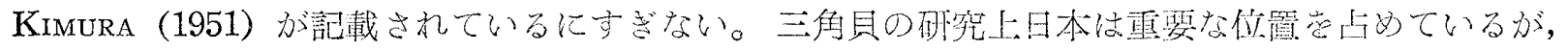

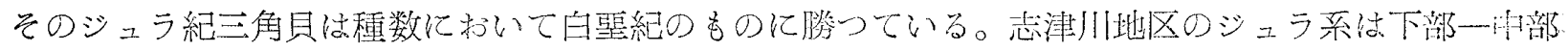

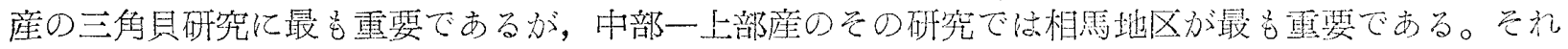

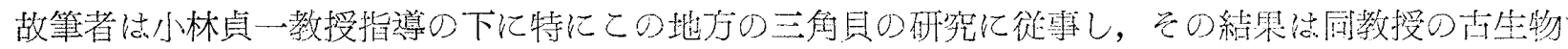

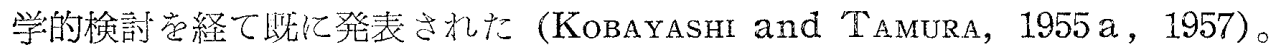

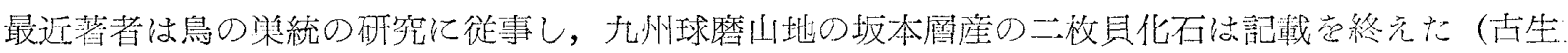

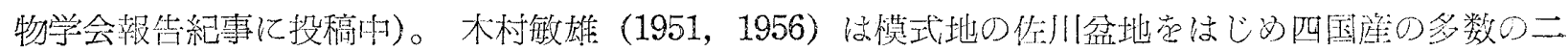

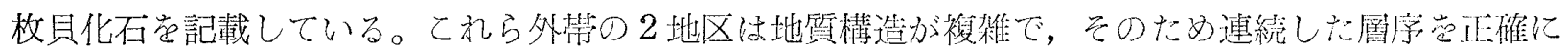

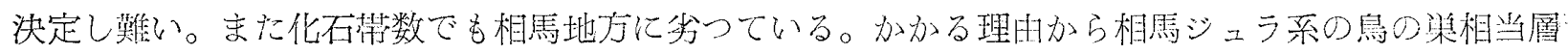

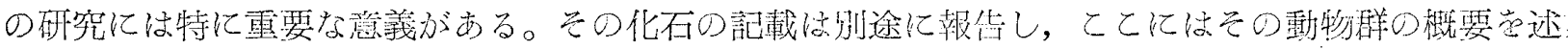
ベる。

日本のジュラ系二枚貝化石中三角貝は極めて重要なもので，烧に報告された本邦シュラ紀三角貝研

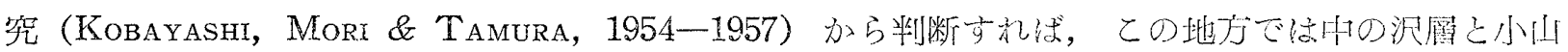
田層复舄の箱相当層と考えるのが妥当である。

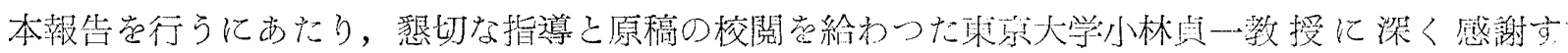

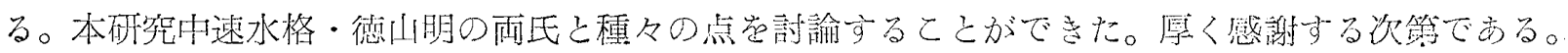

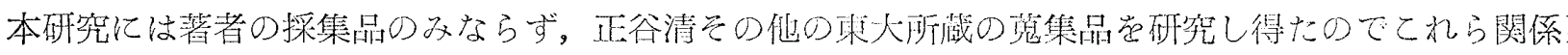
諸賢に厚く感謝する次第である。

\section{2 化石とその産 状}

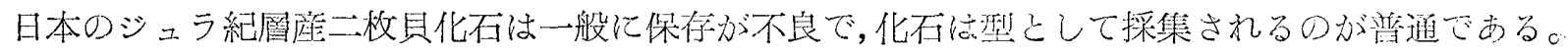

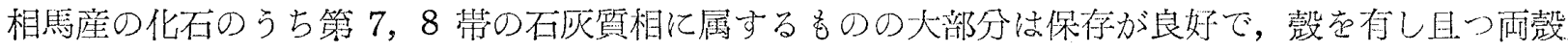
が密着しているものが多い。

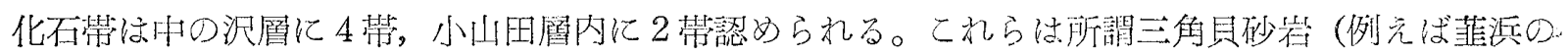


Table 1. Composition of the Soma Jurassic Pelecypod Fauna

\begin{tabular}{|c|c|c|}
\hline Family & Genus & $\begin{array}{l}\text { Number of } \\
\text { Species }\end{array}$ \\
\hline \multirow{5}{*}{$\begin{array}{l}\text { Nuculanidae } \\
\text { Parallellodontidae } \\
\text { Cucullaeidae }\end{array}$} & Nuculana & 1 \\
\hline & Parallellodon & 2 \\
\hline & & \\
\hline & Grammatodon & 2 \\
\hline & Catella & 1 \\
\hline \multirow[t]{3}{*}{ Mytilidae } & & 4 \\
\hline & Modiolus & 3 \\
\hline & Brachidontes & 1 \\
\hline \multirow{6}{*}{$\begin{array}{l}\text { Modiolopsidae } \\
\text { Pteriidae }\end{array}$} & Myoconcha? & 1 \\
\hline & & 8 \\
\hline & Pleria & $\widehat{2}$ \\
\hline & Somapteria & 1 \\
\hline & Pieroperna & 4 \\
\hline & Aulacomyella? & 1 \\
\hline \multirow{7}{*}{$\begin{array}{l}\text { Bakevelliidae } \\
\text { Pinnidae } \\
\text { Pectinidae }\end{array}$} & Gervillia & 1 \\
\hline & Pinna & 1 \\
\hline & & 7 \\
\hline & Chlamys & $\widehat{3}$ \\
\hline & "Aequipecten" & 2 \\
\hline & Campionectes & 1 \\
\hline & Eopecten & 1 \\
\hline \multirow[t]{3}{*}{ Amusiidae } & & 3 \\
\hline & Entolium & $\widehat{2}$ \\
\hline & Somapecten & 1 \\
\hline \multirow{4}{*}{$\begin{array}{l}\text { Plicatulidae } \\
\text { Limidae }\end{array}$} & Plicatula & 1. \\
\hline & & 4 \\
\hline & Lima & $\widehat{3}$ \\
\hline & Ctenostreon & 1 \\
\hline \multirow{5}{*}{$\begin{array}{l}\text { Ostreidae } \\
\text { Trigoniidae }\end{array}$} & Exogyra & 1 \\
\hline & & 6 \\
\hline & Myophorella & $\overparen{4}$ \\
\hline & Oistotrigonia & 1 \\
\hline & Nipponitrigonia & 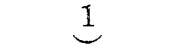 \\
\hline \multirow[t]{3}{*}{ Astartidae } & & 8 \\
\hline & Astarte & $\widehat{6}$ \\
\hline & Opis & 2 \\
\hline \multirow{11}{*}{$\begin{array}{l}\text { Arcticidae } \\
\text { Thraciidae } \\
\text { Cardidae } \\
\text { Pleuromyidae } \\
\text { Corbulidae } \\
\text { Pholadidae } \\
\text { Pholadomyidae }\end{array}$} & Arctica & 1 \\
\hline & Thracia & 1 \\
\hline & Protocardia & 1 \\
\hline & Pleuromya? & 1 \\
\hline & Corbula & 1 \\
\hline & Myopholas & 1 \\
\hline & & 4 \\
\hline & Pholadomya & I \\
\hline & Neoburmesia & 1 \\
\hline & Homomya & 1 \\
\hline & Goniomya & $\underbrace{1}$ \\
\hline 22 & 38 & 61 \\
\hline
\end{tabular}

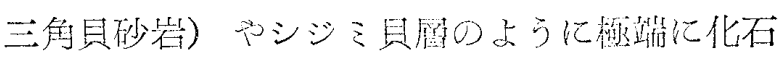

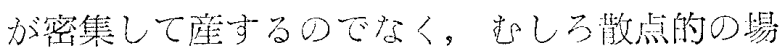
合が多小。炕だ Nipponitrigonia sagawai の みが密集して産することがある。し分し化石層

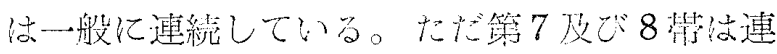

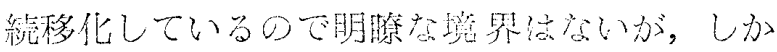
乙含有化石化子つて識则就间能である。筑 5 ,

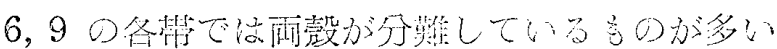

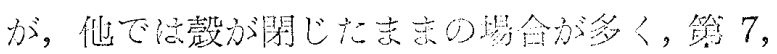

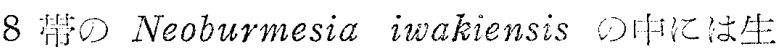

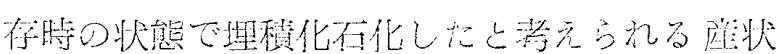

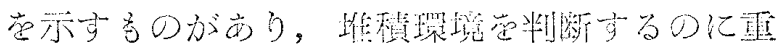
装である。

\section{3 相馬の鳥の巣二枚貝化石群の容相}

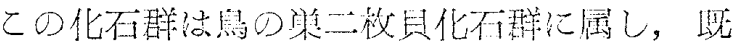
知D作川磨や坂本地区座二枚其化石已其通種为

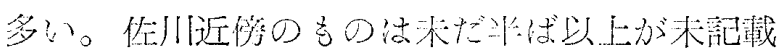

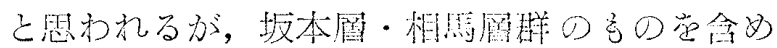
て鳥の笨二枚貝化石群の少く已。 24 科, 47 属,

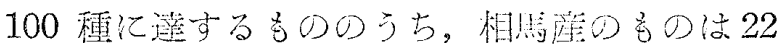

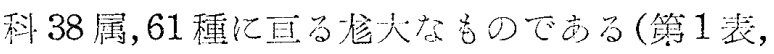
筑 2 表参照)。气して相悲の化石群泣化石带の 数方多いととと化不相の変化汇富んでること が特徽である。Spiti shale P Indonesia, New Zealand $の$ 頁岩相化見分会Inoceramus,

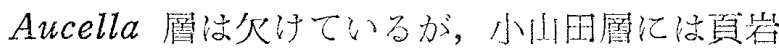

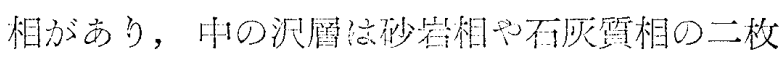
具行富んでいる。

程数の上で本化石群中の主要構成要素はTri一 goniidae, Astartidae, Pteriidae 及び $\mathrm{Pe}-$ ctinidae である。

具の大豆さでは Pinna cf. mitis, Neobur mesia iwakiensis, Homomya gibbosa, Pteria masatanii, Pteroperna? sp., Pteroperna sp., Lima (Plagiostoma) enormicosta, Lima (Plagiostoma) sp., Arctica (Soma-

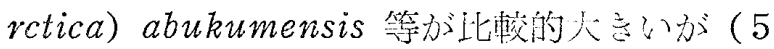
$\sim 10 \mathrm{~cm}$ in length or breadth), 一般化小型 種放多心。 
Tabie 2. List of the Pelecypods in the Upper Jurassic Soma Group

\begin{tabular}{|c|c|c|c|c|c|c|}
\hline & 5 & 6 & 7 & 8 & 9 & 10 \\
\hline 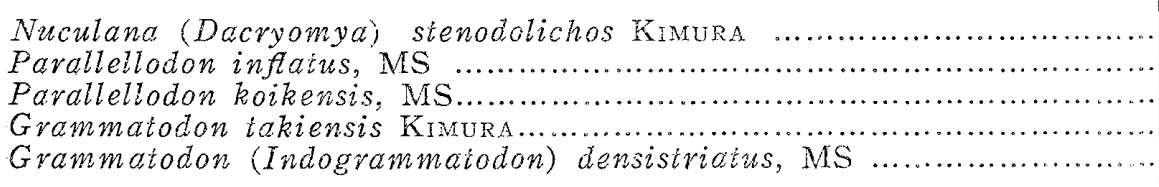 & $\frac{-}{-}$ & $\begin{array}{l}- \\
- \\
-\end{array}$ & $\begin{array}{l}- \\
\bar{x} \\
x\end{array}$ & $\frac{x}{x}$ & $\frac{\bar{x}}{x}$ & $\frac{-}{x}$ \\
\hline 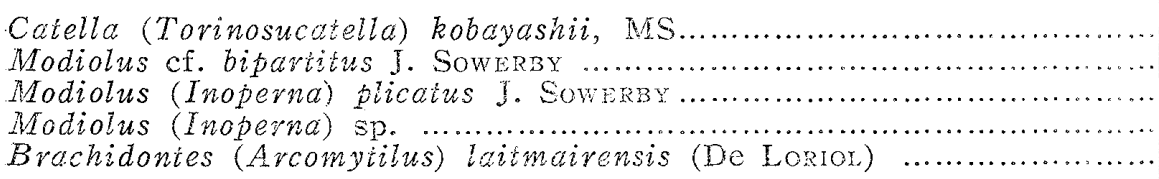 & $\begin{array}{l}- \\
x \\
x \\
-\end{array}$ & 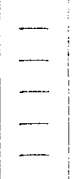 & $\frac{x}{\frac{x}{x}}$ & $\frac{x}{\frac{x}{x}} \frac{x}{x}$ & $\underline{-}$ & $\underline{-}$ \\
\hline 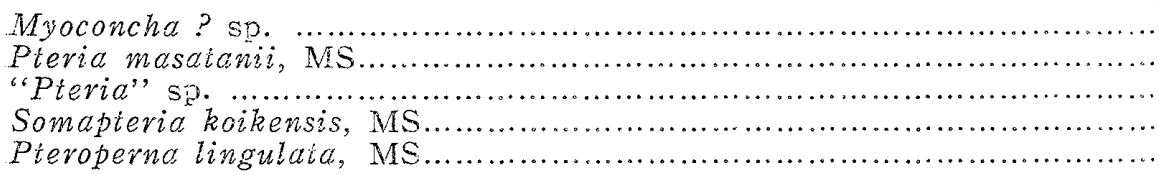 & $\frac{x}{-}$ & - & $\begin{array}{l}\overline{-} \\
\overline{-} \\
\bar{x}\end{array}$ & $\begin{array}{l}- \\
\bar{x} \\
x \\
x\end{array}$ & $\begin{array}{l}- \\
- \\
- \\
-\end{array}$ & $\underline{-}$ \\
\hline 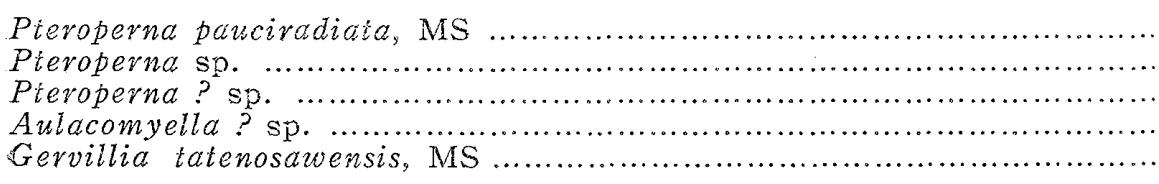 & E & $\begin{array}{l}- \\
- \\
-\end{array}$ & $\begin{array}{l}x \\
x \\
x \\
x \\
x\end{array}$ & $\frac{x}{-}$ & $\begin{array}{l}- \\
- \\
-\end{array}$ & $\begin{array}{l}- \\
- \\
- \\
-\end{array}$ \\
\hline 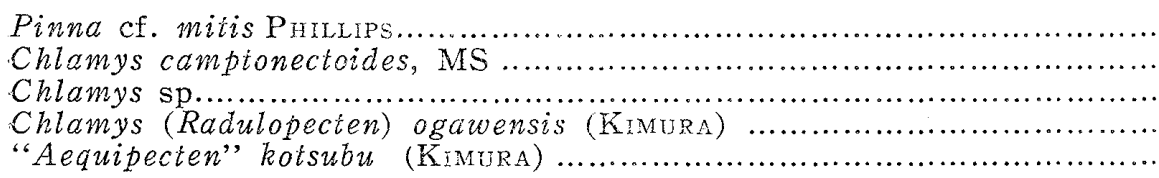 & $\begin{array}{c}- \\
- \\
x \\
x \\
x\end{array}$ & $\overline{-}$ & $\begin{array}{l}x \\
x \\
- \\
x\end{array}$ & $\frac{x}{x}$ & $\begin{array}{l}- \\
- \\
- \\
-\end{array}$ & $\begin{array}{l}- \\
- \\
- \\
-\end{array}$ \\
\hline 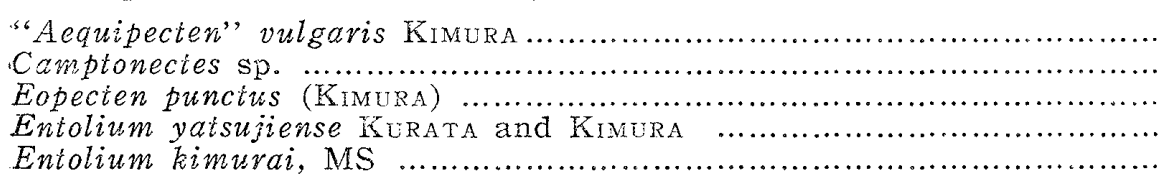 & $\begin{array}{l}x \\
\times \\
x \\
\end{array}$ & $\frac{-}{-}$ & $\begin{array}{l}- \\
- \\
-\end{array}$ & $\begin{array}{l}- \\
- \\
-\end{array}$ & - & $\frac{-}{-}$ \\
\hline 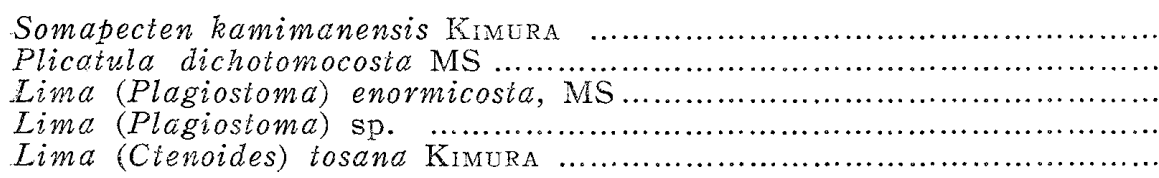 & $\begin{array}{l}x \\
x \\
x \\
x \\
x\end{array}$ & $\frac{x}{E}$ & $\begin{array}{l}- \\
- \\
- \\
-\end{array}$ & $\begin{array}{l}- \\
- \\
-\end{array}$ & $\begin{array}{l}- \\
- \\
- \\
-\end{array}$ & $\begin{array}{l}- \\
- \\
-\end{array}$ \\
\hline 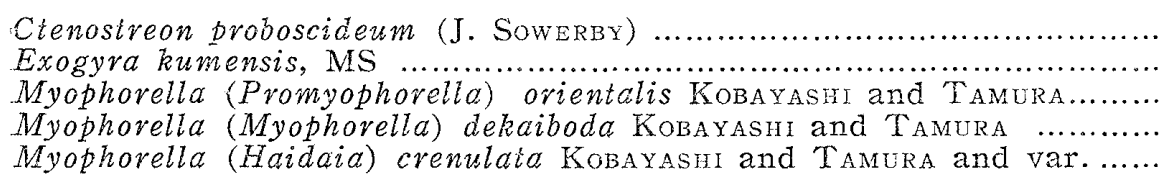 & $\begin{array}{l}x \\
- \\
- \\
x \\
x\end{array}$ & $\frac{-}{-}$ & $\begin{array}{l}- \\
- \\
\bar{x}\end{array}$ & $\frac{\bar{x}}{\bar{x}}$ & $\begin{array}{l}- \\
\bar{x} \\
-\end{array}$ & $\begin{array}{l}- \\
- \\
-\end{array}$ \\
\hline 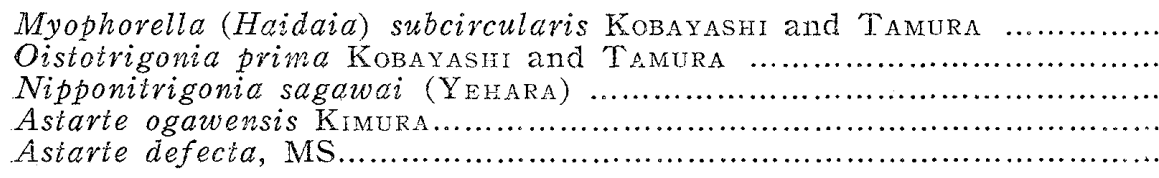 & $\begin{array}{l}x \\
x \\
x \\
x \\
x\end{array}$ & $\frac{x}{x}$ & $\begin{array}{l}- \\
- \\
-\end{array}$ & $\begin{array}{l}- \\
- \\
-\end{array}$ & $\begin{array}{l}- \\
- \\
-\end{array}$ & $\begin{array}{l}- \\
- \\
-\end{array}$ \\
\hline 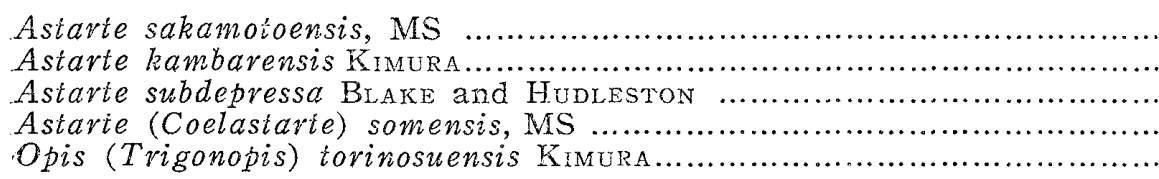 & $\begin{array}{l}x \\
x \\
x \\
x \\
x\end{array}$ & $\begin{array}{l}- \\
- \\
-\end{array}$ & $\frac{-}{\frac{x}{x}}$ & $\frac{x}{\bar{x}}$ & $\begin{array}{l}- \\
\times \\
x \\
-\end{array}$ & $\begin{array}{l}- \\
\times \\
\times \\
-\end{array}$ \\
\hline 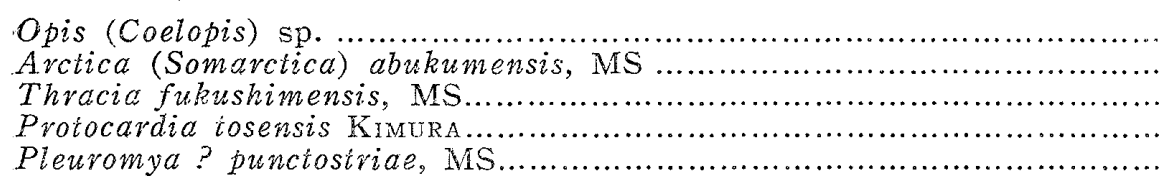 & $\frac{x}{x}$ & $\begin{array}{l}- \\
- \\
-\end{array}$ & $\begin{array}{l}- \\
\bar{x} \\
x \\
-\end{array}$ & $\begin{array}{l}- \\
- \\
x \\
x \\
x\end{array}$ & $\begin{array}{l}- \\
- \\
-\end{array}$ & $\underline{-}$ \\
\hline 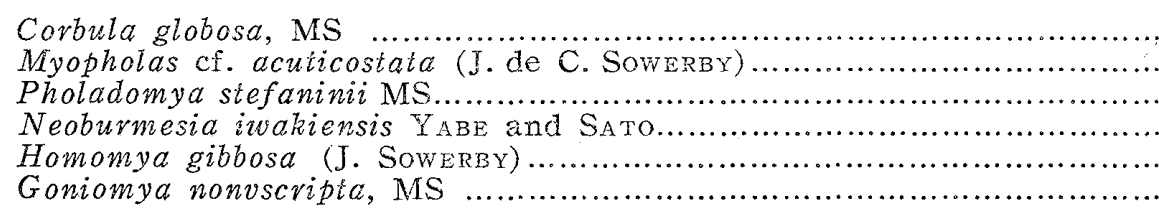 & $\begin{array}{l}-\frac{x}{x} \\
- \\
-\end{array}$ & $\begin{array}{l}- \\
- \\
-\end{array}$ & $\frac{\bar{x}}{\frac{\bar{x}}{x}}$ & $\begin{array}{l}x \\
x \\
x \\
x \\
x\end{array}$ & $\begin{array}{l}- \\
- \\
- \\
-\end{array}$ & $\frac{x}{-}$ \\
\hline
\end{tabular}


個体数として佉 Grammatodon takiensis, Chlamys (Radulopecten) ogawensis, Somapteria koikensis, Gervillia tatenosawensis, Pinna cf. mitis, Neoburmesia iwakiensis, Goniomya nonvscripta, Protocardia tosensis, Astarte sakamotoensis, Astarte subdepressa, Corbula globosa, Myonhorella (Haidaia) crenulata var. lunulata, Nipponitrigonia sagawai, Entolium

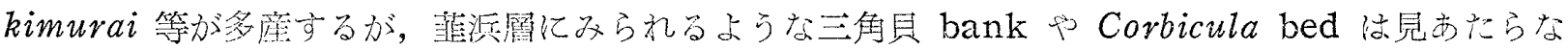
い。

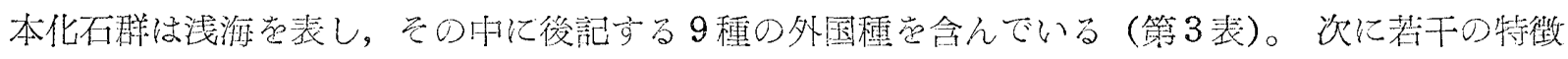
的な事項営あげると，

(1) Inoceramus や Aucella などの泥相飞特街的な化石学产しない。

(2) ヒマラヤ特にエチオピヤ区に多産守る Eligmus-Gryphaea 化不群がみつかつていない。

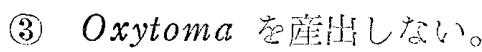

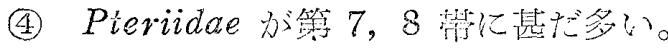

(5) Somapecten, Nipponitrigonia, Haidaia, Somapteria, Neobrrmesia, Somarctica 等つ特

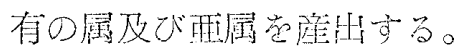

Table 3. Geological range of the Euro-Asiatic Species of the fauna

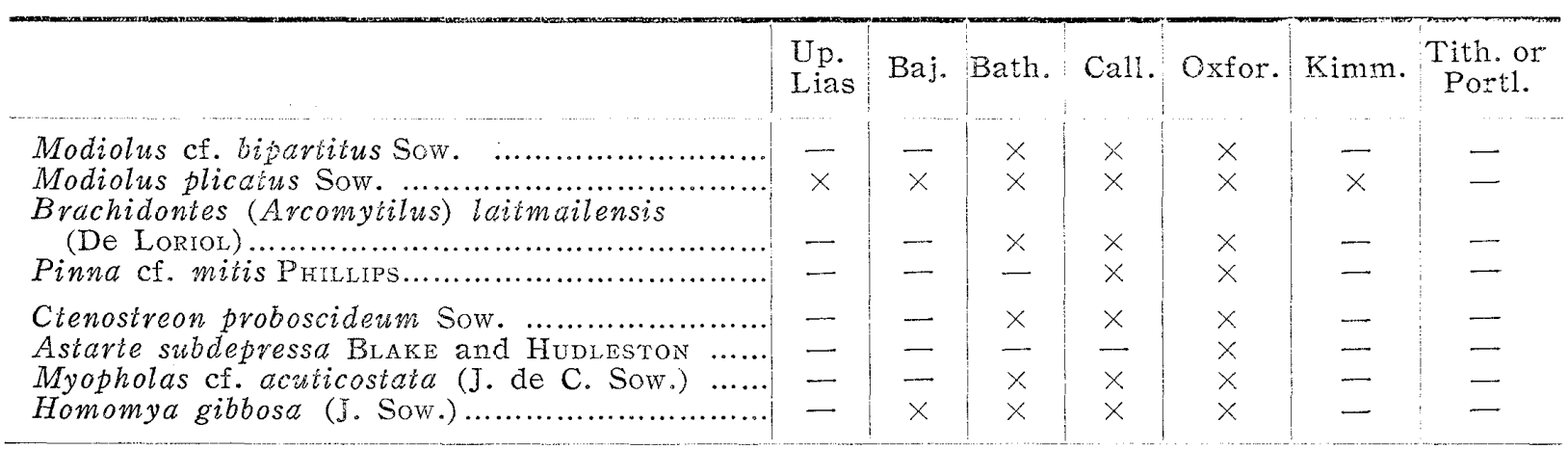

\section{4. 棲 息 環 境 の 考 察}

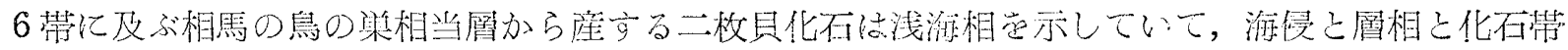
との関係は管1図の如くである。

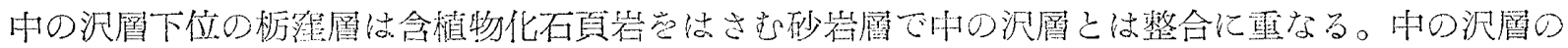

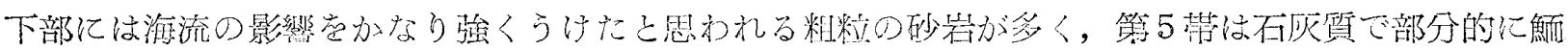

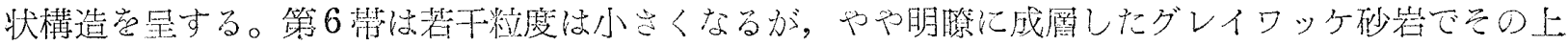

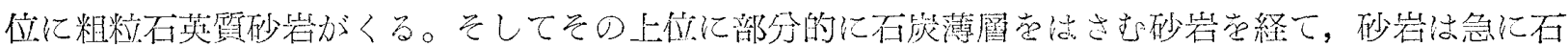

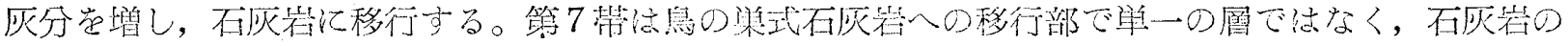

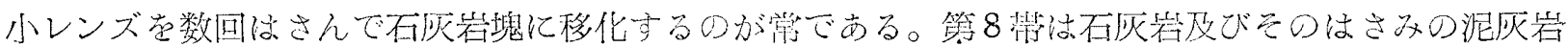

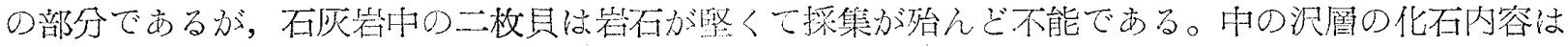

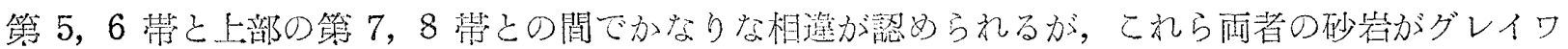

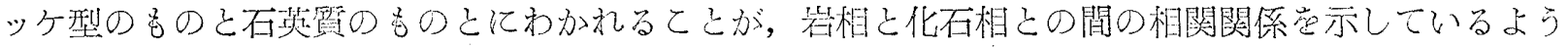
である。

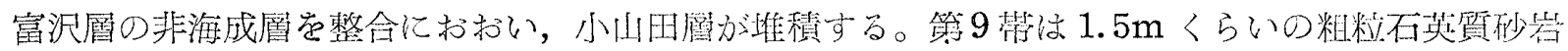

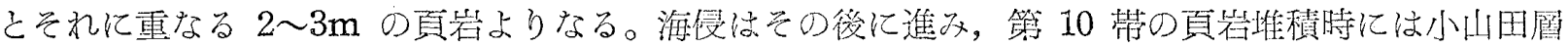

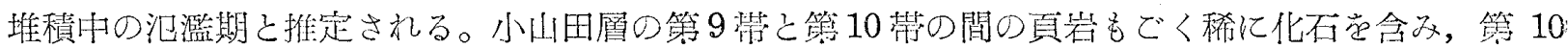




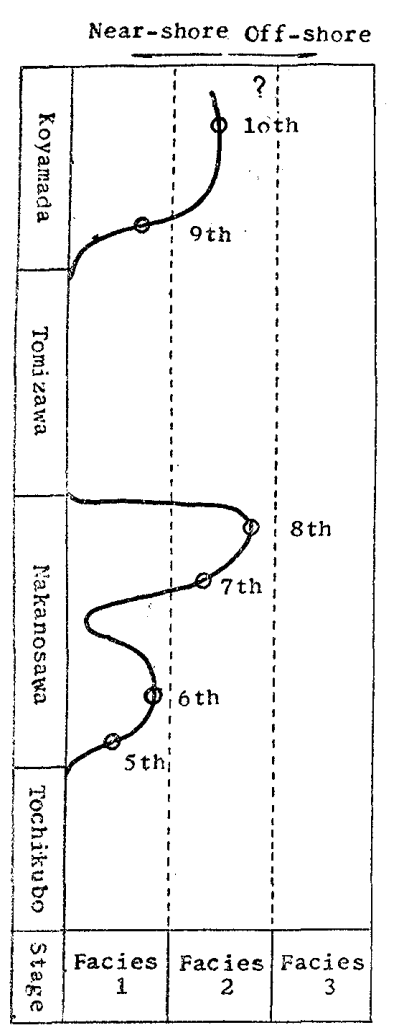

Fig. 1 Graph showing the oscillation of the strandline of the Torinosu-Sea in Soma district and the fossil zones.

Facies 1: 三角具砂岩等 の秒岩相 (ss facies)

2：石圧相及び随州する 貝岩相 (calcareous \& shaly facies)

3: 頁岩相 (shaly facies)

5 th 10 th: 第 5 化石㻭

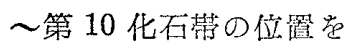
示す.
带は明かな化石層定示さない。

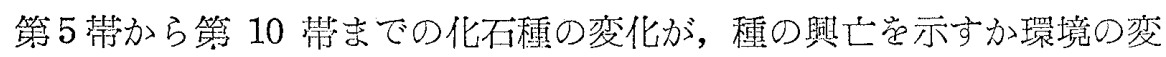

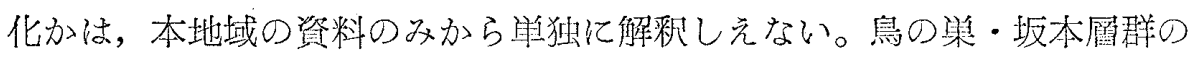
既知二枚貝㞾加えて判断すると，化石带間の種の変化は酋相の違い之関係

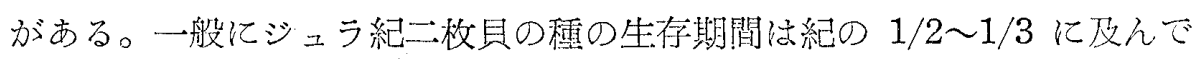
いる。

砂管相の化石は分布が広く，世界的な桩肪りさえもつことは，欧・ヒマ

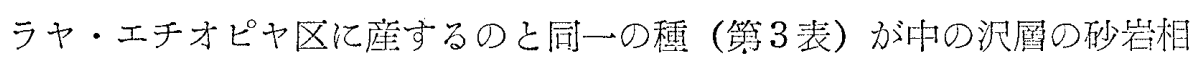

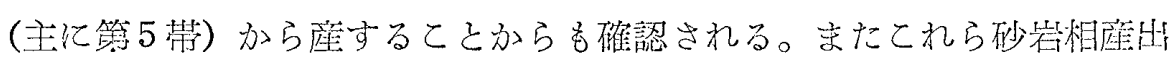

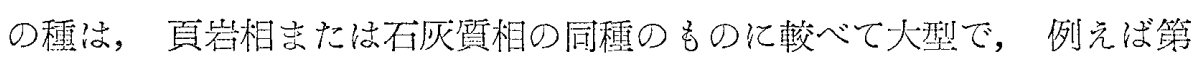
7 蒂 (石灭質相) 産の Astarte subdepressa の多くは小型で，砂等相に 属する䈍 5，9 苧のものは大型である。Grammatodon takiensis につい

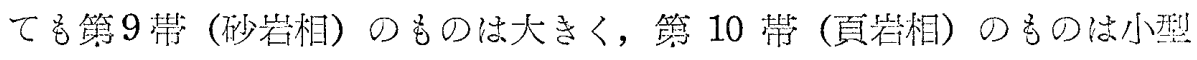

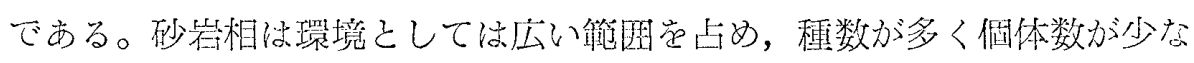
いととが一般に恋吅られている。Nipponitrigonia sagawai 学除き, 多

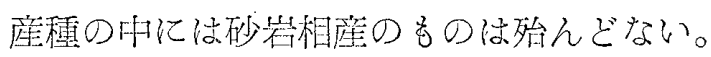

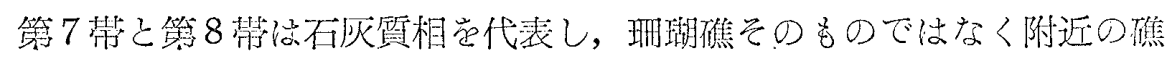

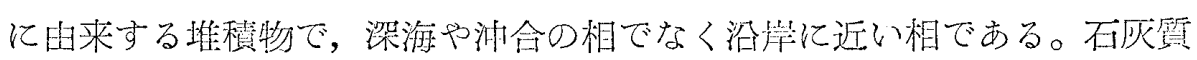
相は砂岩相にくらべると確わに環境としては特殊化しているが，種の数は

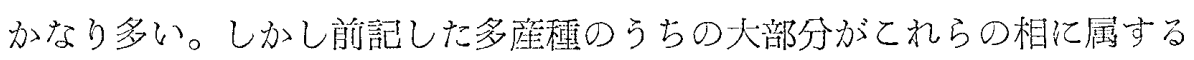

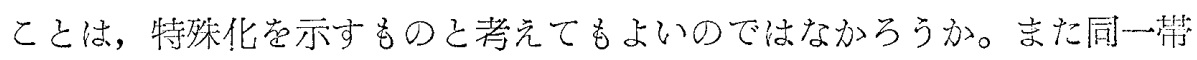
由局地的な特殊化も激しい。例えば Somapteria abukumensis は䈍 8 带

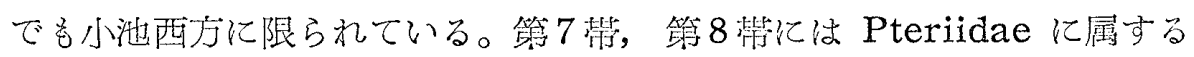

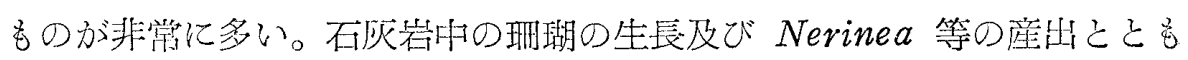

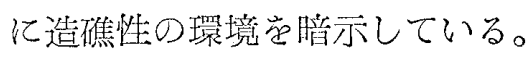

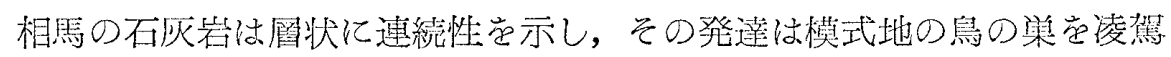

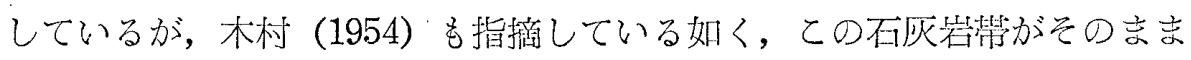
礁自体ではなく，多くのレンズ状石灰岩の集会である。Neoburmesia iwakiensisが生存時の状態峞保つて産出したり，他の二枚具でも殼㟒とじ たままのものが砂吡相中のものにくらべて多いてとや，不死岩の罒理があ まり明らかでないととから，海流の溞さは砂崖相にくらべて遙が弱く， また坂本層の石灰岩に較べても微弱であつたと思われる。

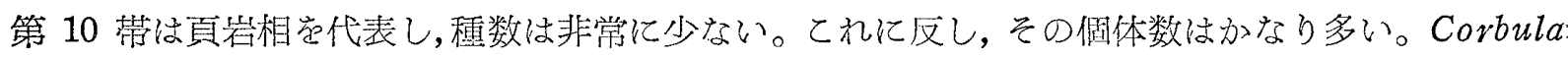
globosa, Grammatodon takiensis, Astarie kambarensis, Entolium kimurai 等の小型種で, Entolium kimurai は坂本地区では外洋に近いと考えられる西半部に少なく，内陸に近い東半部に。

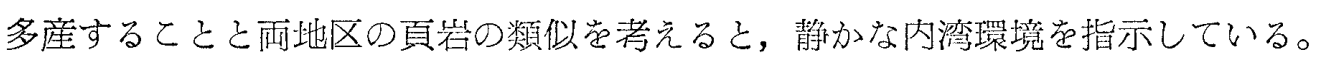

相馬の化石二枚貝をしらべた結果の程度で溹,

Lima, Camptonectes, Plicatula, Myophorella, Nipponitrigonia, Somapecten

等力㳅少岩相の如く浅海の比較的外洋環境によく成育し，

Somapteria, Gervillia, Pteria, Pteroperna, Thracia, Neoburmesia

は Calcareous facies の静かな内湾にすみ，面岩相には属として特徴的なものはない。 
種として砂毕相に比較的多いものは，

Grammatodon (Indogrammatodon) densistriatus, Entolium yatsujiense, Somapecten kamimanensis, Lima (Plagiostoma) enormicosta, Plicatula dichotomocosia, Astarie (Coelastarte) somensis, Arctica (Somarctica) abukumensis, Myophorella dekaiboda, Myophorella (Haidaia) crenulata, Myophorella (Haidaia) subcircularis, Nipponitrigonia, sagawai

石灭質相化多いものは，

Parallellodon inflatus, Catella (Torinosucatella) kobayashii, Chlamys camptonectoides,

Pteroperna lingulata, Pteroperna pauciradiata, Somapteria koikensis, Gervillia

tatenosawensis, Pinna cf. mitis, Neoburmesia iwakiensis, Astarte sakamotoensis 頁岩相には，

Entolium kimurai, Astarte kambarensis, Corbula globosa

そして広感性のものとしては次のものがあげられる。

Grammatodon takiensis, Protocardia tosensis, Astarte subdepressa

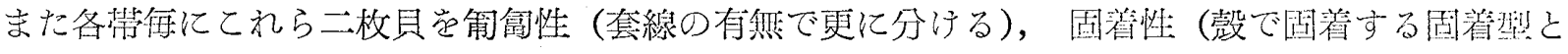
足絲で固着する附着型に分ける)，呀孔型，遊泳型に分け筑 4 表に示した。

Table 4. Composition of the Fauna, classified by habit (taking genus as a unit and accepting its habit as generally known)

\begin{tabular}{c|r|r|r|r|r|r|r|r}
\hline No. of zone & & 5 th & 6 th & 7 th & 8 th & 9 th & 10 th \\
\hline Creeping species & 25 & 18 & 3 & 8 & 14 & 4 & 4 \\
with sinus & 7 & 3 & 0 & 3 & 7 & 0 & 1 \\
without sinus & 18 & 15 & 3 & 5 & 7 & 4 & 3 \\
\hline Sedentary species & 27 & 10 & 0 & 16 & 14 & 2 & 1 \\
attached by one valve & 4 & 3 & 0 & 1 & 1 & 0 & 0 \\
attached by byssus & 23 & 7 & 0 & 15 & 13 & 2 & 1 \\
\hline Boring species & 1 & 1 & 0 & 1 & 0 & 0 & 0 \\
\hline Swimming species & 8 & 6 & 2 & 0 & 0 & 0 & 1 \\
\hline Total & 61 & 35 & 5 & 25 & 28 & 6 & 6 \\
\hline
\end{tabular}

（各種についての運動樣式はその属から一般的に決めたものである）

\section{5. 指 示化石としての意義}

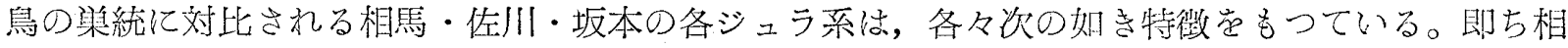

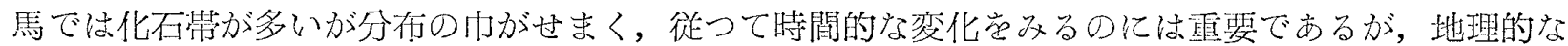

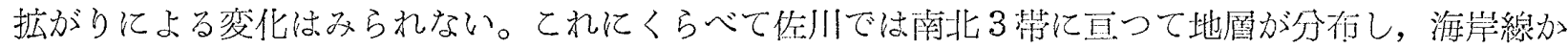
らの距離による層相の変化がみられ，坂本地区では外洋から内沙への相の樍の変化が楒められる。し

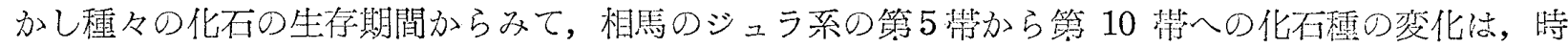
間の経過よりもむしろ海侵海退に件う屏相変化がてれ范支配していると考えられる。

相馬の二枚只は化石群しして佐川及び坂本のそれと極めて類似したものであり，てれらの動物群は 相互に対比される。同時代の手取統の化石群の容相は未だ明らかではないが牧戸の動物群と法極めて 買つたものであり，桐谷のものとも生存期間が長く分不の広い Nipponitrigonia sagawai 范除いて 共通種はないようである。 


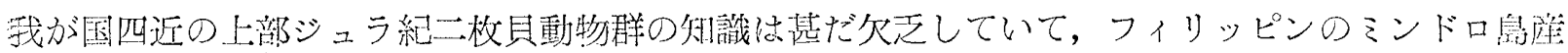

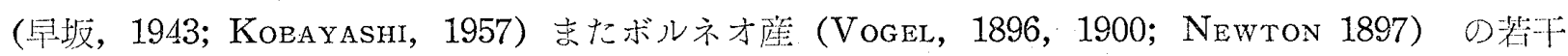
の化不が記載されている以外には較べるべきものがない。しかしボルネオ産の Haidaia ミンドロ应

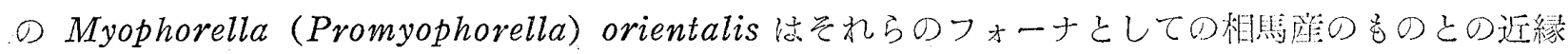
性范隐示している。

ニュージランド (Marwick, 1953)，インドネシャ (Boenm, 1904) 及び Spiti (Holdhaus,

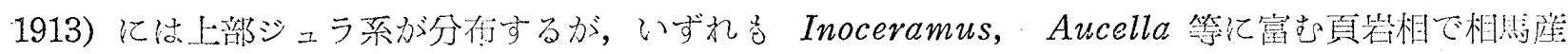
のものには其通檑がない。

Cutch 苍屾とするヒマラヤ区（Cox，1940，1952），ソマリーランド営中心とするエチオピヤ区 (Cox 1935, 1936; Dietrich, 1933; Daceué, 1904; Diaz-Romero, 1931; Newton, 1895; Stefanini,

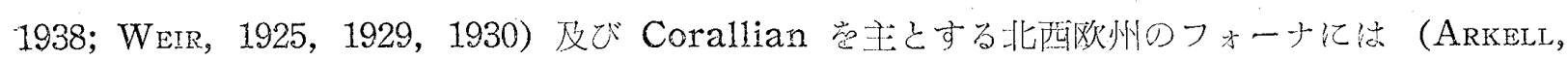

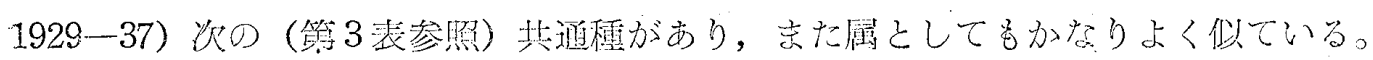

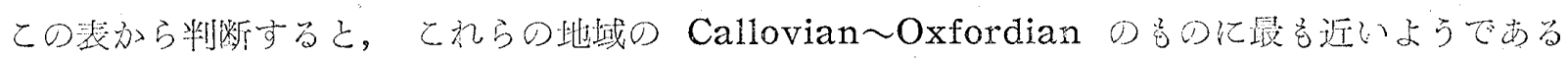

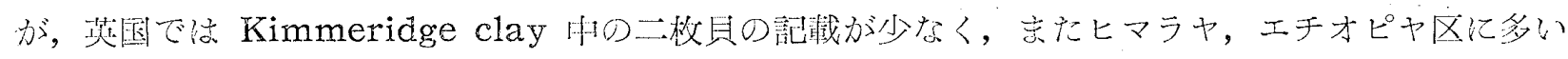

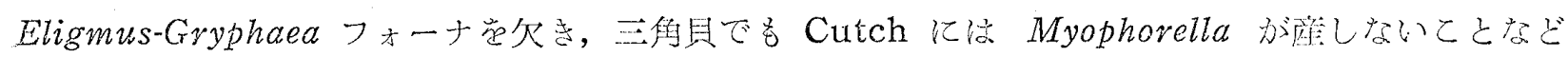

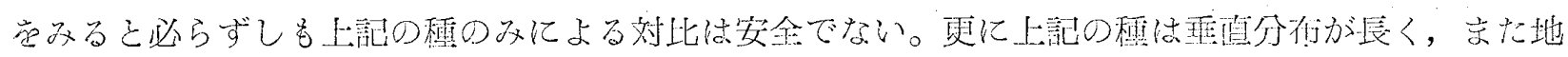

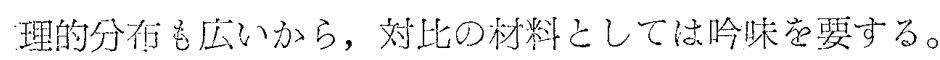

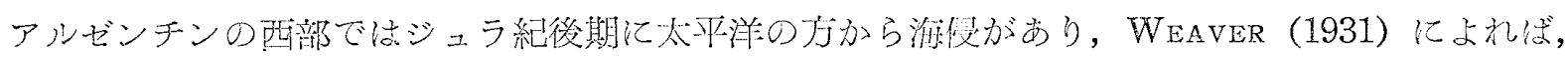

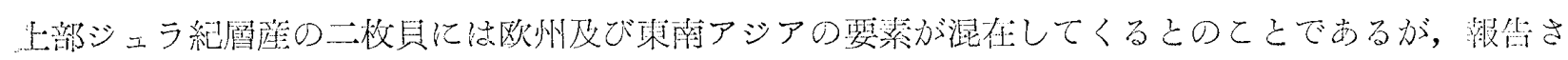

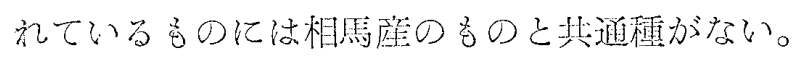

メキシコ・米国南部諸州 (ImLAY，1940，41，45) 及び Malone Jurassic (CRAGIN, 1905) 飞も

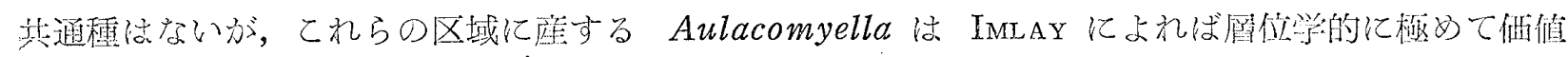
の高いもで,ソマリーランド, Dalmatia, 合浔国の Southern States 及びメキシコの Mid-

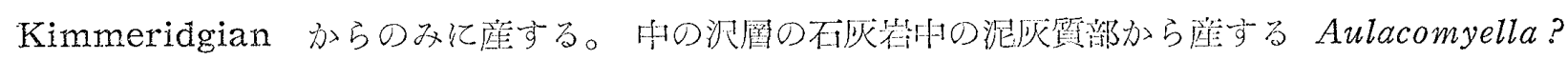

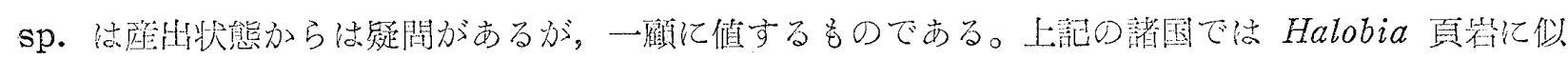

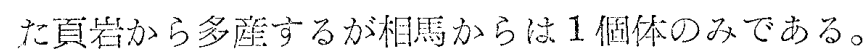

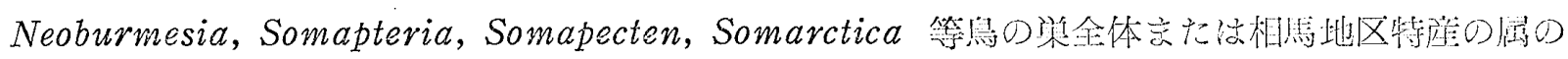

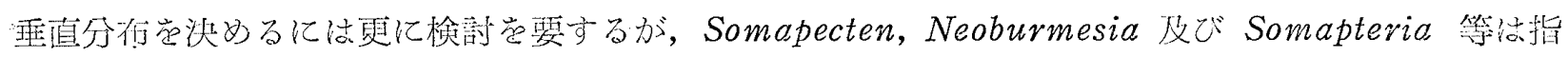
時者として重要と思われる。他には Pecten 類及び三住具が対比に有効と慙う。

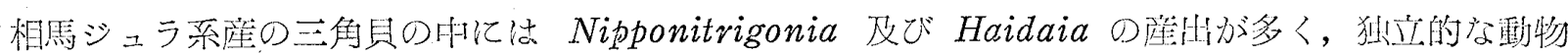

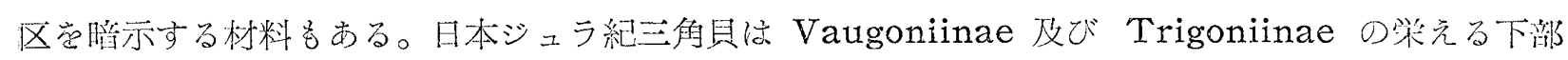

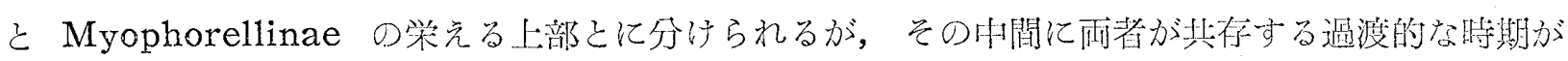

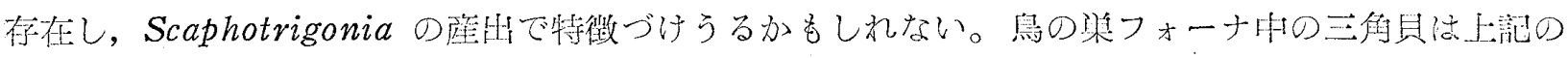

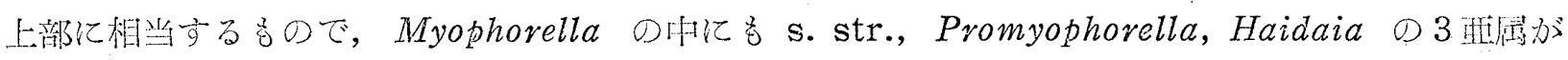

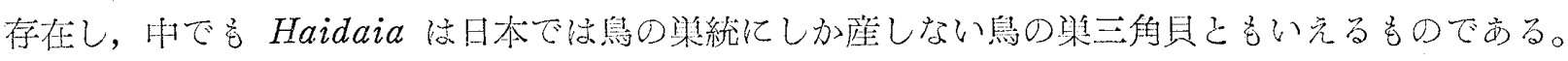

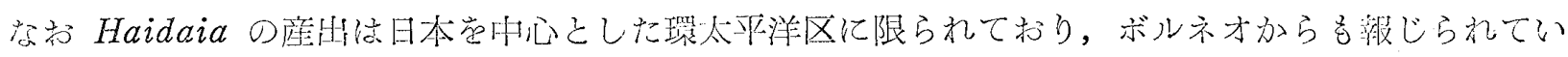

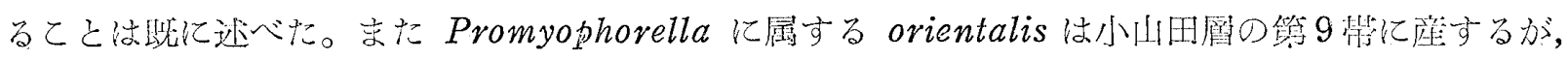

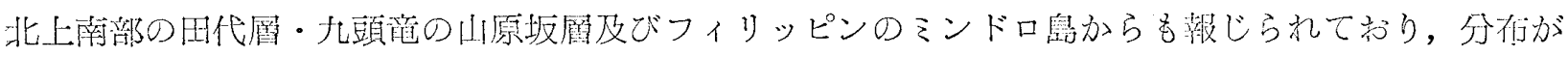
広い。Nipponitrigonia sagawai はこの属の十では祖先型であるが，日本国内での分街㳂く，四

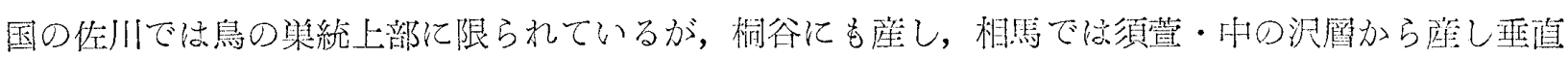
分有が大きい。 
相馬産の鳥の策二枚貝化石は比較的保存良好なものが多く，次の如巻特質を有する。

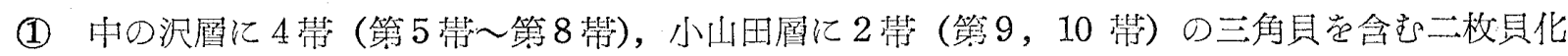

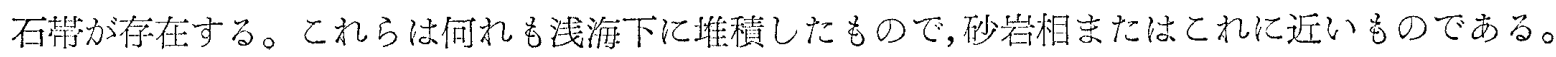
(2) 島の楽二枚貝勳物群の一貝で， 22 科，38 属，61 種に旦る大き学動物群で, Pectinidae, Pteriidae, Astartidae 及び Trigonidae 亿属するものが多い。Inoceramus,Aucella 等蕰含 むSpiti 頁岩の如き頁䇹相のものは殆んどなく，距離的に邀いヒマラヤ・エチオピヤ・北西欧州 の上蔀シュラ系産の二枚貝には 9 種の共通種がある。しかしてれらの区域に特徴的な EligmusGryphaea フォーナが存在也ず，また三角具からも日本に多産する Myophorella が Cutch に 産しないことや, Somapecten, Neoburmesia, Somapteria, Nipponitrigonia 等の独自な属の 存在は，上記の地区の二枚具とは心なり異つた独立的動物区学腤示している。そして恐らくボル ネオ及びフィリッピンのミンドロはこれに属する。

(3) 日本の舄の且統以外の上部シュラ系のうち，北上山地のものとは尿相の違いがかなり目立ち，

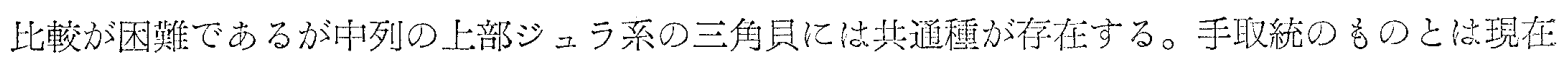
のととろ三角貝種歘除いては共通種がなく，恐らく非常に異つたものであろう。

交献

Arkeld, W. L. (1929-37) : A Monograph of British Corallian Lamellibranchia. Pal. Soc. London. Bовнм. G. (1904): Beiträge zur Geologie von Niederlandisch-Indien. Erste Abteilung. Die Südküsten der Sula-Inseln Taliabu und Mangoli. Erste Abschnitt. Grenzschichten zwischen Jura und Kreide. Palaeontographica, Suppl. 4.

Cox, L. R. (1935) : Jurassic Gastropoda and Lamellibranchia. In the Mesozoic Palaeontology of British Somaiiland. (1936): Fossil Mollusca from Southern Persia (Iran) and Bahren Island. Pal. Indica, N. S. Vol. 22, Mem. No. 2.

(1940 \& 52): The Jurassic Lamellibranch Fauna of Kuchh (Cutch). Pal. Indica. Ser. 9, Vol. 3, Pt. 3. \& Pt. 4.

CragrN, F. W. (1905): Palaeontology of the Malone Jurassic Formation of Texas. Bull. U. S. Geol. Surv. No. 266.

Dacqué, E. (1904): Beiträge zur Geologie des Somalilandes, 2. Teil, Oberer Jura. Beitr, Palaeont. und Geol. Oesterreich-Ungarns und des Orients, Bd. 17.

Dinz-Romero, V. (1931): Contributo Allo Studio della Fauna Giurese della Dancalia Centrale. Palaeontographia Italica, Vo1. 31.

Dietrich, W. O. (1933): Zur Stratigraphie und Palaeontologie der Tendaguruschichten. Palaeontographica Supp1. 7. 2 Reihe, Teil 2.

早坂一郎 (1943): フィリピン群島ジュラ紀層について, 附三解具属についての記事, 台湾地学記事.Vo1。 14, Nos. $1-2$.

Holdhaus, K. (1913): Fauna of the Spiti Shales (Lamellibranchiata and Gastropoda). Pal. Indica, Ser.15, Vol. 4, Pt. 2, Fasc. No. 4.

Imlay, W. R. (1940): Upper Jurassic Pelecypods from Mexico. Jour. Palaeont. Vol. 14, No. 5. (1941): Jurassic fossils from Arkansas, Loisiana and eastern Texas. Jour. Palaeont.

Vol. 15 , No. 3. 
Imlay, R. W. (1945): Jurassic from the Southern States, No. 2, Jour. Palaeont. Vol. 19, No.3. Kimura, T. (1951): Some Pectinias and a Limid from the Jurassic Torinosu Group in Japan. Jour. Fac. Sci. Univ. Tokyo, Sec. 2, Vol. 7, Pt. 7.

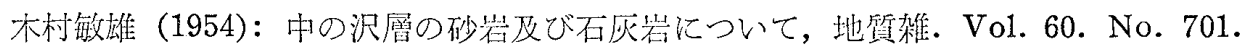

KIMURA, T. (1956): Some Pelecypods from the Upper Jurassic Torinosu Group in Kochi Prefecture, Japan. Jour. Earth Sci., Nagoya Univ., Vol. 4, No. 2.

Kobayasmi, T. (1935): Contribution to the Jurassic Torinosu Series of Japan. Jap. Jour. Geol. Geogr. Vol. 12.

Kobayashi, T. and others. (1954-75): Studies on the Jurassic Trigonians in Japan. Pts. 1-6. Jap. Jour. Geol. Geogr. Vol. 25-28.

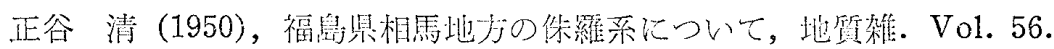

Newtor, B. B. (1895): On a Collection of Fossils from Madagascar obtained by the Rev. R. Baron. Q. J. G. S. Vol, 51.

(1897): On a Jurassic Lamellibranch, etc. from the Sarawak River Limestone of Borneo, with a Sketch of the Mesozoic Fauna of that Island. Geol. Mag. N. S. Dec. 4, Vo1. 4. Shimizu, S. (1930): Notes on two Tithonian species of Perisphinctes from Torinosu limestone of Koike, Prov. Iwaki. Jap. Jour. Geol. Geogr., Vol. 7,No. 2.

Stefanini, G. (1938): Molluschi del Giuralias della Somalia. Gastropoda e Lamellibranchi. Pal. Iialica. 32, Supp. 4 .

由村 実 (1954)：日本産体羅紀三伤具の研究，地質雑. Vol. 60 .

Vogel, F. (1896): Neue Mollusken aus dem Jura von Borneo. Samml. geol. R.-Mus. Leiden, Bd. 5 .

(1900): Neue Mollusken aus dem Jura von Borneo. Ibid. Bd. 6.

Weaver, C. E. (1931): Palaeontology of the Jurassic and Cretaceous of West Central Argentina. Mem. Univ. Washington, Vol. 1.

WeIR, J. (1925): Brachiopoda, Lamellibranchiata, Gastropoda and Belemnites. Mon. Geol. Depi. Iunterian Museum, Glasgow Univ., 1.

(1929): Jurassic Fossils from Jubaland, East Africa, collected by V.G. GLENDAY, and the Jurassic Geology of Somaliland. Ibid., 3.

(1930): Mesozoic Brachiopoda and Mollusca from Mombasa. Ibid., 4.

YABE, H. and SATo, S. (1942): A new Bivalve from the Jurassic Torinosu Series of the Abukuma Mountainland. Proc. Imp. Acad. Tokyo. Vol. 18. 